\title{
RECALCULATION OF LABORATORY TESTS WITH THE EXTENDED ZONE METHOD
}

\author{
Marcus Achenbach ${ }^{\mathrm{a}}$,Guido Morgenthal ${ }^{\mathrm{b}}$ \\ ${ }^{a}$ LGA KdöR, Nürnberg, Germany \\ ${ }^{\mathrm{b}}$ Bauhaus Universität Weimar, Chair of Modelling and Simulation of Structures, Weimar, Germany
}

\begin{abstract}
The Advanced Calculation Method given in EN 1992-1-2 is accepted by engineers and building authorities for the determination of the fire resistance of reinforced concrete structures. It has been developed originally for the recalculation of laboratory tests: the time of failure is calculated for a given layout of reinforcement. But in the structural analysis of concrete columns, the area of reinforcement has to be calculated for a desired fire resistance. Design methods and strategies, which are suitable for the design of concrete compression members, require constant material properties and strain limits, which are not given for the Advanced Calculation Method. Therefore Achenbach and Morgenthal have proposed an extension of the Zone Method by Hertz, suitable for the implementation in commercial design software. In this paper, this Extended Zone Method is used to recalculate laboratory tests to determine the accuracy of this method. A statistical analysis of the results is performed to evaluate the statistical key data of the Extended Zone Method.
\end{abstract}

Keywords:reinforced concrete, simplified analysis, calibration

\section{INTRODUCTION}

The Zone Method has been developed by Hertz (1981) as a scheme for the manual calculation of the fire resistance of reinforced concrete cross sections. It is part of DIN EN 1992-1-2 (2006), where it is contained as simplified calculation method. But the description of the Zone Method in the code is incomplete, which led to misinterpretations in Germany. Therefore the use in Germany is only allowed with further assumptions (DIN EN 1992-1-2/NA, 2010), as described by Zilch, Müller andReitmeyer (2010) or Cyllok and Achenbach (2009). Zilch et al. (2010) introduce the thermals strains in their proposal for the use of the Zone Method - which is in contradiction to the basic assumptions from Hertz (1981). Cyllok and Achenbach (2009)assume to consider the effect of the hindered thermal strains on the compressed reinforcement by a reduced strength of the reinforcing steel. But the proposed reduction from Cyllok and Achenbach is only empiric and the basic assumptions of the Zone Method and its limits have not been determined.

Therefore Achenbach and Morgenthal(2015) review the concept of the Zone Method by Hertz and propose an enhanced method, called Extended Zone Method, to consider the effect of the hindered thermal strains of the reinforcement. The accuracy of this method is demonstrated by recalculation of one laboratory test with the Extended Zone Method and the Advanced Calculation Method (DIN EN 1992-1-2, 2006). It can be shown, that the shape of the moment-curvature-relationship and the calculated time to failure are comparable to each other.

But only one recalculated example is not sufficient to proof the accuracy of the Extended Zone Method. Therefore a larger number of laboratory tests are recalculated and the results are processed by statistical methods to obtain reliable statistical key data for further examinations.

\section{EXTENDED ZONE METHOD}

Achenbach and Morgenthal (2015) propose an extension of the Zone Method by Hertz as a calculation scheme suitable for the implementation in commercial design software. The idea is to keep as much as possible from the method developed by Hertz (1981) and to propose only slight modifications. 
The considered cross section, subjected to fire on all surfaces, is displayed in Fig. 1. The assumptions of the Extended Zone Method are:

1. thermal stains and stresses can be neglected,

2. the concrete cross section is reduced by $a_{z, E I}$,

3. the concrete is represented with a constant temperature $\theta_{M}$ using the stress-strain curves of the Advanced Calculation Method,

4. the peak strain of the concrete $\left|\varepsilon_{c 1, \theta}\right|$ is at least $3.5 \%$,

5. the stress-strain curves of the Advanced Calculation Method are used for the reinforcement,

6. the strength of the compressed reinforcement is reduced by $\eta_{s}(\theta)$.

The assumptions 1 to 5 are in accordance with the Zone Method described by Hertz (1981). The temperature dependent strength of the concrete $f_{c, \theta}$ and the reinforcement $f_{s, \theta}$ used in the Zone Method are derived from the stress-strain-curves given in DIN EN 1992-1-2 (2006). Therefore the use of these material models is also in compliance with the Zone Method.Assumption 6 is introduced by Achenbach and Morgenthal (2015) to simulate the effect of the thermal strains on the compressed reinforcement.

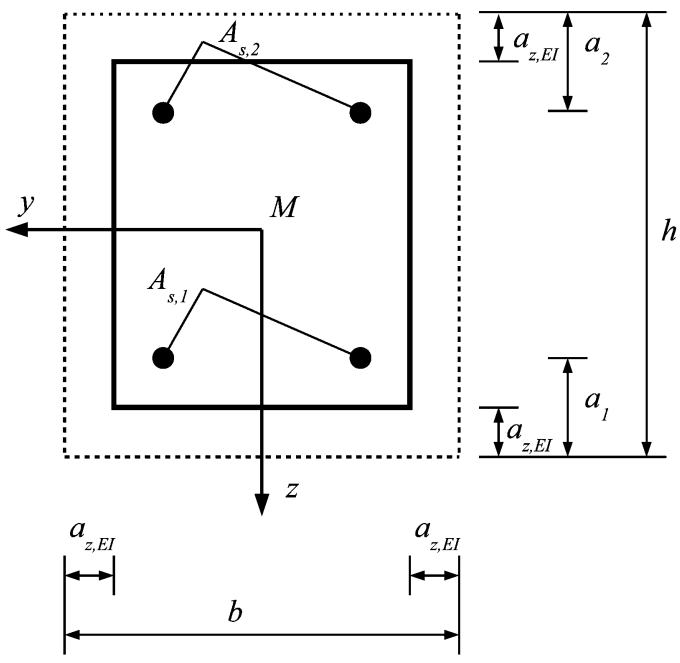

Fig. 1 Cross section for the Extended Zone Method

For a rectangular cross section with $b<h$, the mean strength for a section through the centroid parallel to $y$ is given by:

$$
k_{c, m}=\frac{\int_{-\frac{b}{2}}^{\frac{b}{2}} k_{c}(\theta) d z}{b},
$$

with $k_{c}(\theta)=f_{c, \theta} / f_{c k}, f_{c, \theta}=$ concrete strength at temperature $\theta$. The height of the "damaged" zone for the compressed cross section given in Fig. 1 is defined by:

$$
a_{z, E I}=\frac{b}{2} \cdot\left(1-\left(\frac{k_{c, m}}{k_{c}\left(\theta_{M}\right)}\right)^{4 / 3}\right) \text {. }
$$

Background information on the validity of this equation proposed by Hertz (1981) is given by Achenbach and Morgenthal (2015).

To consider the effect of the thermal strains on the compressed reinforcement, Achenbach and Morgenthal (2015) propose to reduce the area of the reinforcement by $\eta_{s}(\theta)$ :

$$
\eta_{s}(\theta)=\left\{\begin{array}{rl}
1, & 20{ }^{\circ} \mathrm{C} \leq \theta<100{ }^{\circ} \mathrm{C} \\
0.5-0.5 \cdot \frac{\theta-400{ }^{\circ} \mathrm{C}}{300{ }^{\circ} \mathrm{C}}, & 100{ }^{\circ} \mathrm{C} \leq \theta<400{ }^{\circ} \mathrm{C}, \\
0.5, & 400{ }^{\circ} \mathrm{C} \leq \theta \leq 1200{ }^{\circ} \mathrm{C}
\end{array} \quad \varepsilon \leq 0\right.
$$


where: $\theta=$ temperature of the reinforcement $\left[{ }^{\circ} \mathrm{C}\right]$. For reinforcement under tension, the reduction factor is defined by $\eta_{s}=1.0$.

\section{RECALCULATION OF LABORATORY TESTS}

\subsection{Test database}

The laboratory tests from TU Braunschweig, Université de Liège and Ghent Universiteit are used for recalculation. The tested structural systems and cross sections are displayed in Fig. 2, the range of parameters is described in Table 1.All columns have been heated on all sites by a standard fire (DIN EN 1991-1-2, 2010), the compressive strength at the day of the test has been measured and the yield strength of the reinforcement has been determined.

Table 1Range of parameters of experimental tests

\begin{tabular}{ccc}
\hline parameter & unit & range \\
\hline length: $l_{\text {col }}$ & {$[\mathrm{m}]$} & 2.10 to 5.76 \\
cross section: $b \times h$ & {$[\mathrm{~cm}]$} & $20 \times 20,30 \times 20,30 \times 30,30 \times 40,40 \times 40$ \\
concrete cover of rebars: $c_{n o m, l}$ & {$[\mathrm{~cm}]$} & 2.3 to 4.0 \\
rebars: number $\times \mathrm{d}$ & {$[\mathrm{mm}]$} & $6 \varnothing 12,6 \varnothing 14,4 \varnothing 16,8 \varnothing 16,4 \varnothing 20,6 \varnothing 20,4 \varnothing 25,10 \varnothing 25$ \\
yield strength of rebars: $f_{y k}$ & {$[\mathrm{MPa}]$} & 404 to 591 \\
concrete compressive strength: $\beta_{W t}$ & {$[\mathrm{MPa}]$} & 29 to 53 \\
eccentricity of applied loads: $e_{0}$ & {$[\mathrm{~mm}]$} & constant: 0 to 600, inversely: \pm 15 and \pm 30 \\
applied axial force: $\left|N_{0}\right|$ & {$[\mathrm{kN}]$} & 90 to 1695 \\
\hline
\end{tabular}
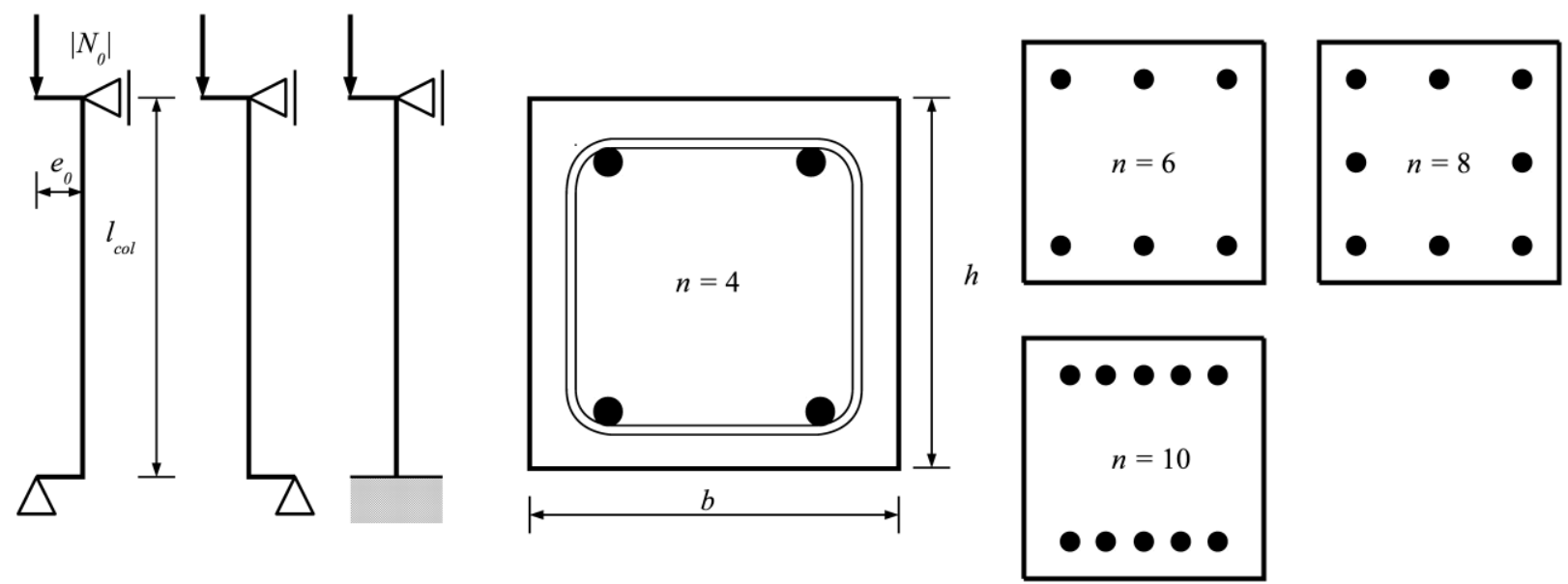

Fig. 2 Structural systems and cross sections of the laboratory tests

The tested columns from Germany are described in the reports fromTU Braunschweig (Klingsch et al., 1977, Haß and Klingsch, 1980, Haß, 1987), a summary is given in the Ph.D. thesis from Haß (1986). But there are slight differences in the documentation: 52 tests are listed in the reports, 47 are listed at Haß. Three tests have been cancelled and the description for one test is incomplete. For some of the remaining 48 columns, the documentation is inconsistent. In that case, the data given by Haß- which is more detailed compared to the reports - has been used for recalculation.

The columns tested in Belgium are documented by Dotreppe et al. (1996). A total number of 25 tests have been carried out, but only for eight columns the testing regime is comparable to the tests from TU Braunschweig. These columns have been heated by a standard fire under a constant load until failure and are therefore used for recalculation. 


\subsection{Calculation methods}

A finite difference scheme (Baehr and Stephan, 1998) is used for the calculation of the temperatures of the cross section. The temperature distribution of the concrete cross section is determined for each time step $\Delta t=1 \mathrm{~min}$ and stored for the cross section analysis. The moment-curvature diagramis evaluated for the given time steps: the resisting moment for a given curvature and the load of the considered column is calculated by iteration. This description of the load bearing behaviour of the columns is used to derive the ultimate resisting moment and the curvature depended stiffness of the analysed cross section. The state of strain is calculated with a transfer matrix method (Petersen, 1982). The column is divided into 10 sections, assuming a constant stiffness in each section. The column fails, when no equilibrium can be found or the ultimate resisting moment is exceeded.

\subsection{Modelling of material properties}

For the calculation of the temperatures the following physical properties according to the Eurocode (DIN EN 1991-1-2, 2010, DIN EN 1992-1-2, 2006) are taken into account: a moisture content of $3 \%$, the thermal conductivity with its lower limit, a density of $2400 \mathrm{~kg} / \mathrm{m}^{3}$, an emissivity of 0.7 , a heat-transfer coefficient of $25 \mathrm{~W} / \mathrm{m}^{2} \mathrm{~K}$.

Hot rolled reinforcement and concrete with siliceous aggregates with the material models given in DIN EN 1992-1-2 (2006) is used for recalculation. The concrete strength $\beta_{W, t}$, given by Haß (1986) and Dotreppe et al. (1996), has been measured at the age of test with $200 \mathrm{~mm}$ cubes. The equivalent cylinder strength $f_{c k}$ is calculated by Eqn. (4) with the factors proposed by Schnell and Loch (2009):

$$
f_{c k}=k_{150} \cdot k_{c y l} \cdot k_{\text {cure }} \cdot \beta_{W, t}=1.05 \cdot 0.8 \cdot 0.92 \cdot \beta_{W, t}=0.77 \cdot \beta_{W, t}
$$

where: $k_{150}=$ strength of $150 \mathrm{~mm}$ cubes $/ 200 \mathrm{~mm}$ cubes, $k_{c y l}=$ strength of cylinders $/$ cubes, $k_{\text {cure }}=$ strength of wet cured / dry cured concrete.

\subsection{Statistical evaluation}

The ratio $\eta=t_{c a l} / t_{\text {exp }}$ is evaluated statistically, with: $t_{c a l}=$ experimental time of failure and $t_{\text {exp }}=$ experimental time of failure. It is assumed, that the data follows a normal distribution. Grubbs' test (Rinne, 2008) is used to detect outliers in the data base and the Anderson-Darling test (Rinne, 2008) is applied to check the goodness of fit after removing the suspected outliers.

\section{$4 \quad$ RESULTS}

The time of failure is recalculated for 56 tests using the Extended Zone Method. The statistical key data for $\eta$ are a mean value $\mu=1.18$ and a standard deviation $\sigma=0.55$. The histogram displayed in Fig. 3 reveals, that there are outliers in the data base.

Using the statistical tests by Grubbs and Anderson and Darling at a level of significance $\alpha=0.1$ leads to the exclusion of seven outliers. Four tests from Belgium and three tests from Germany are rejected. Two of the excluded tests from Germany are also not contained in the Ph.D. thesis from $\mathrm{Ha}$ (1986). It is not possible to clarify the cause of those outliers with the documented specifications in the test reports.

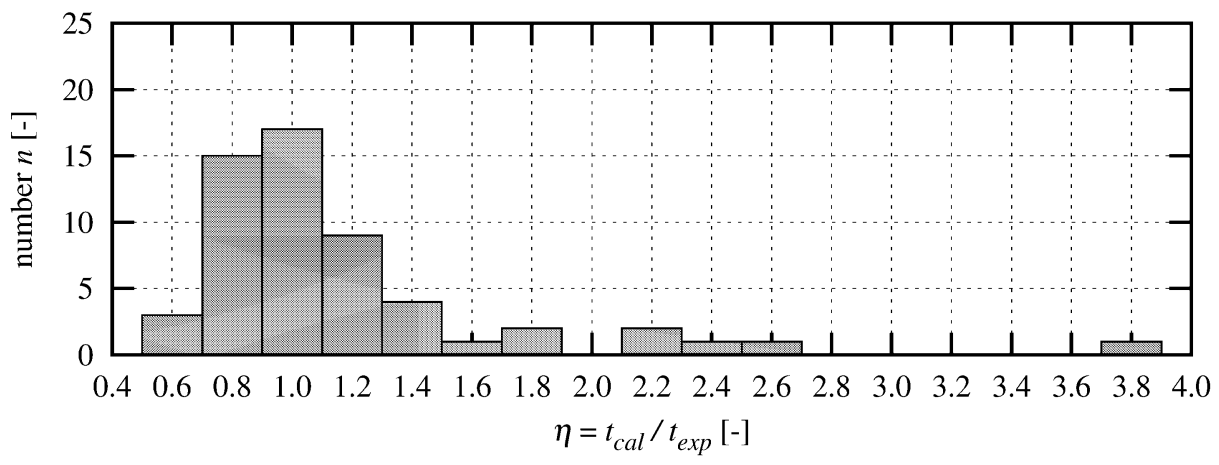


Fig. 3 Histogram for $\eta=t_{c a l} / t_{\text {exp }}$ of all recalculated laboratory tests
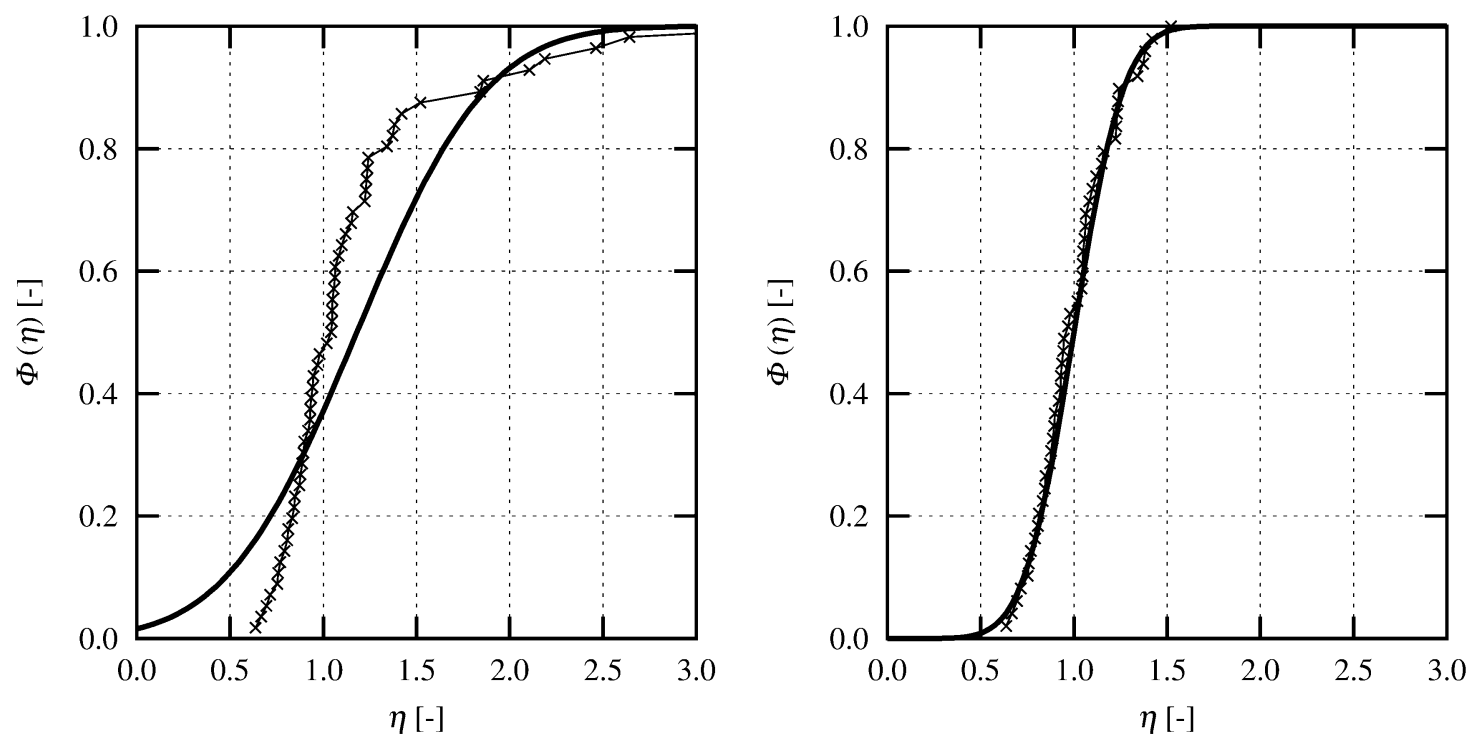

Fig. 4 Cumulative density function for $\eta=t_{\text {cal }} / t_{\text {exp }}$ of recalculated laboratory tests for the expected (-) and measured values (x), left side: with outliers, right side: without outliers

After the removal of the suspected outliers, the statistical key data changes to $\mu=1.00$ and $\sigma=0.21$. The cumulative density function with and without outliers is displayed in Fig. 4. It is obvious, that the assumption of a normal distribution is not justified, if all results are considered for the calculation of the parameters of the model uncertainty (Fig. 4, left). Using the statistical methods described in section 3.4 leads to parameters for a normal distributon, which is in accordance with the results from the recalculation of laboratory test (Fig. 4, right).

The statistical key data of the Extended Zone Method is comparable to the results given by Haß (1986) and Achenbach and Morgenthal(2014) for the Advanced Calculation Method. Haß calculates the parameters $\mu=0.97$ and $\sigma=0.21$ using material properties, which differ partly from DIN EN 1992-1-2. The results have not been processed statistically, though outliers are obvious.Achenbach and Morgenthal use the material properties from DIN EN 1992-1-2 and exclude outliers from the data base. The statistical key data for the Advanced Calculation Method is specified here with $\mu=$ 0.76 and $\sigma=0.17$.

\section{CONCLUSIONS}

The Extended Zone Method proposed by Achenbach and Morgenthal has been used for the recalculation of laboratory tests of reinforced concrete columns heated by a standard fire. The laboratory tests from Belgium and Germany - with a comparable testing regime - have been considered. A total number of 56 columns have been recalculated and the results have been processed using an outlier and goodness of fit test. The histogram, the plot of the cumulative density and the statistical tests for $\eta=t_{c a l} / t_{\text {exp }}$ reveal, that there are outliers in the data base. Rejecting seven outliers from the calculated results leads to the statistical key data $\mu=1.00$ and $\sigma=$ 0.21, which is comparable to the results for the Advanced Calculation Method. Therefore the Extended Zone Method can be considered to be verified by the accuracy of the recalculation of laboratory tests.

But to proof an adequate safety level of the Extended Zone Method compared to the widely accepted Advanced Calculation Method, it is necessary to examine the reliability for a reasonable set of examples using both methods. It is not possible to conclude an equal safety level from the results of the calibration, because the sensitivities against the input parameters and the influence of model uncertainties can differ. 


\section{REFERENCES}

Achenbach, M., Morgenthal, G., 2015.Extension of the Zone Method of Eurocode 2 for Reinforced Concrete Columns Subjected to Standard Fire. Journal of Structural Fire Engineering. - Accepted for publication.

Achenbach, M., Morgenthal, G., 2014. Vollprobabilistische Analyse von Stahlbetonwänden unter Brandeinwirkung. Bauingenieur 89, pp. 478-486.

Baehr, H. D., Stephan, K., 1998. Wärme- und Stoffübertragung, 3rd Edition.Springer, Berlin.

Cyllok, M., Achenbach, M., 2009. Anwendung der Zonenmethode für brandbeanspruchte Stahlbetonstützen. Beton- und Stahlbetonbau 104, pp. 813-822.

DIN EN 1991-1-2, 2010. Eurocode 1: Einwirkungen auf Tragwerke - Teil 1-2: AllgemeineEinwirkungen Brandeinwirkungen auf Tragwerke.

DIN EN 1992-1-2, 2006. Eurocode 2: Bemessung und Konstruktion von Stahlbeton- und Spannbetontragwerken - Teil 1-2: Allgemeine Regeln - Tragwerksbemessung für den Brandfall.

DIN EN 1992-1-2/NA, 2010. Nationaler Anhang - National festgelegte Parameter - Eurocode 2: Bemessung und Konstruktion von Stahlbeton- und Spannbetontragwerken - Teil 1-2: Allgemeine Regeln Tragwerksbemessung für den Brandfall.

Dotreppe, J.-C., Franssen, J.-M., Bruls, A., Baus, R., Vandevelde, P.,Minne, R., van Nieuwenburg, D., Lambotte, H., 1996. Experimental research on the determination of the main parameters affecting the behavior of reinforced concrete columns under fire conditions.Magazine ofconcreteresearch49, pp. 117127.

Haß, R., 1986. Zur praxisgerechten brandschutztechnischen Beurteilung von Stützen aus Stahl und Beton. Ph.D. Thesis, Technische Universität Braunschweig.

Haß, R., 1987. Brandversuche an Stahlbeton- und Verbundstützen. InSonderforschungsbereich 148 Brandverhalten von Bauteilen - Arbeitsbericht 1984-1986, Teil I/A. Technische Universität Braunschweig, pp. 80-99.

Haß, R., Klingsch, W., 1980. Parameterunteruntersuchungen zum Brandverhalten von Stahlbetonstützen Versuche und theoretische Begleitung.InSonderforschungsbereich 148 - Brandverhalten von BauteilenArbeitsbericht 1978-1980, Teil I. Technische Universität Braunschweig, pp. 91-111.

Hertz, K., 1981. Design of fire exposed concrete structures. Report 160,Technical University of Denmark, Institute of Building Design, Lyngby.

Klingsch, W., Haksever, A., Walter, R., 1977. Brandversuche an Stahlbetonstützen - Versuchsergebnisse und numerische Analyse. InSonderforschungsbereich 148 - Brandverhalten von Bauteilen - Arbeitsbericht 1975 / 77, Teil I. Technische Universität Braunschweig, pp. A 1-2-1 - A-1-2-18.

Petersen, C., 1982. Statik und Stabilität der Baukonstruktionen, 2nd Edition. Vieweg, Wiesbaden.

Rinne, H., 2008. Taschenbuch der Statistik, 4th Edition. Harri Deutsch,Frankfurt.

Schnell, J., Loch, M., 2009. Umrechnung historischer Baustoffkennwerte auf charakteristische Werte. Der Prüfingenieur 34, pp. 50-61.

Zilch, K., Müller, A., Reitmayer, C., 2010. Erweiterte Zonenmethode zur brandschutztechnischen Bemessung von Stahlbetonstützen. Bauingenieur 85, pp. 282-287. 